\title{
Teaching Summative Writing within an Introductory Sociology Course: Do Paragraph Frames Improve Students' Writing Skills?
}

\author{
Pamela Pitman Brown* \\ College of Arts \& Sciences, Albany State University, 504 College Drive, Georgia 31705 , United States \\ Colleen R. Bennett \\ College of Arts \& Sciences, Albany State University \\ Theodosia A. Lovette \\ College of Arts \& Sciences, Albany State University \\ Carol Ann Ham \\ College of Education \& Human Services, Valdosta State University
}

\begin{abstract}
This article describes the use of a summary writing assignment within an intro sociology course for application of sociological knowledge to current events. Summative writing is paramount to moving through the college curriculum, yet students struggle to be able to begin summary writing exercises, often procrastinating until the last moment, and thus are unsuccessful. Scripts or summary frames are also helpful in the transition to academic language acquisition skill-building, noting scripts, even for speech, provide scaffolding. Thus low states summary writings such as in introductory sociology courses are allowing students to build upon their learned skill as they move through into their upper level discipline focused courses. The skill is transferable to all disciplines and is not relegated to discipline specificity. The following article describes a Time 1/Time 2 assessment of the use of summary frames, with Time 1 using non-prompted writing within the assignment, and Time 2 using prompted writing within the assignments. Additionally, an assessment of the Readability Flesch-Kincaid is considered.
\end{abstract}

Keywords: Writing Prompts, Summative Writing, Introduction courses, Sociology

DOI: $10.7176 / \mathrm{JEP} / 10-29-09$

Publication date:October $31^{\text {st }} 2019$

\section{Introduction}

Recent articles lament the writing skills of college students (Migliaccio \& Carrigan, 2017; Relies \& Tierney, 2013, Goode, 2010; Lillis \& Turner, 2011), and in all honesty this has been on ongoing lamentation for many years (Cadwallander \& Scarboro, 1982). As "writing for communication within the discipline" is frequently part of programmatic learning objectives, there is a struggle as to how to teach skills to undergraduates which should have been acquired at a lower level of education, such as high school. The implementation of "writing across curriculum" (WAC) movement has brought writing in courses other than English into the realm of conceptualization of learning, which allows the students a transferability of knowledge and skills between their courses (Murphree, 2014).

This renewed emphasis on writing skills for communication as well as teaching theoretical application allowed the author to create a project to do both: Sociology in the News. As the initial writing project moved across the semesters, the author noted that there were numerous issues within asking for summative statements from the news sources. Firstly, the students did not understand how summary writing is constructed. Many simply thought that meant cutting and pasting several lines from the article they were reading, and thus a "summary" is completed. Secondly, even with the addition of the phrase, "in your own words" the summary was still consistently being constructed with several cut and paste sentences. Thirdly, after speaking with students, the author found that one phrase repeated often, "How do I start the sentence?" Thus, the first author began searching for ways to introduce the summary writing skills within an introductory sociology course including the addition of prompts for which the student can "start" the sentence.

This is not a new concept within sociology courses, as Parrott and Cherry (2014) created a process memo to improve student writing within sociology courses, which allowed a writing dialogue to occur between the student and the instructor. Their process required students to write/answer questions and reflect upon their writings, in other words creating a dialogue on their writing process with their instructor. This process encouraged revisions along the way.

\subsection{Summary Writing}

Summary writing is a basic skill, which is introduced typically during one's early education (middle school) but may not be mastered until a later time. Summary writing is very common within the lower-level (Freshmen/Sophomore) courses in a college or university setting, and numerous instructors use short "summary 
writing" exercises as a way to check whether the student has indeed read the material assigned and has understood/comprehended the meaning of the material. Some educators believe that summary writing may be the most important writing skill that a college/university student can acquire. The earlier the skill is acquired in college/university the more proficient the student should be when they reach the upper level courses, and research methods. It is an important skill when writing a final thesis/senior paper, or a research proposal, where we often insert summaries of our readings (books, journal articles). The University of North Carolina Charlotte's Sociology Program (University of North Carolina Charlotte Website, 2018) notes "summary writing" as a low-stakes assignment, or "writing to learn." However, they also note "analysis of current issues or events" as medium stakes papers. Thus incorporating both levels of written work into one project is a way to transition students from the low-stakes into the medium-stakes writing across the semester or the curriculum.

\subsection{Summary Composing}

Summary composing is a key skill needed within high school and college courses, and allows the student to move into academic language. As Finley (2014) notes, moving into academic language, or instructional and discipline related language, allows the student to become proficient in the information flow within academics. Williams (2018) also notes that mastering directional words such as analyze, argue/convince, compare/contrast, summarize, demonstrate, describe, explain, interpret, infer allow students to be more successful in standardized testing as well as in writing assignments.

\subsection{Paragraph Frame}

Using a paragraph frame consisting of pre-written sentence starters (Zwiers, 2008), students may be able to achieve summary writing skills in introductory courses outside of English, which will assist them in furthering their education. Finley (2014) also brings attention to using scripts or summary frames in the transition to academic language acquisition skill-building, noting scripts, even for speech, provide scaffolding for young learners. Taraba (2015) has a wonderful list of transitional words/phrases that can assist in the creation of summary frames, paragraph frames, or scripts.

\section{Classroom Exercise}

\subsection{Initial Exercise}

Several years ago, universities began noting within institutional learning objectives and program learning objects that incorporating application of discipline contexts to current events should be trickled down to each course. It was during this time that one of the authors began using "sociology in the news" whereby the students had to locate current articles (within the last six months) and apply the course material learned to the article. Thus, understanding of application of a theory or a concept could be translated into the "real world problems" of today. As Haber (2008), one way to have students become interested in a topic is to use current headlines in order to demonstrate the relevancy of the materials within the course, as well as engaging the students. Karasik (2012) posits that with the current cohort of students, it is important to also understand how the students obtain their news/current events, and utilize strategies for assisting them to locate the materials needed. Karasik also suggest that if possible the instructor could bring in a current news article.

The initial instructions were posited as follows:

During the class, you will locate 4 current news articles (these can be from reputable online news sources such as Time/Newsweek/The Wall Street Journal/The New York Times and the local paper/news channels, concerning real world issues, particularly from a sociological perspective. Each news article is worth 25 points toward your grade. The following procedure should be used. Use the proper format:

\section{Name}

Date

Title of article *(include the hyperlink to the article so we can locate it)

Write a two paragraph summary of the article. Then include a third paragraph detailing WHY this is an important article for the class. Link the article to any material we have covered in the course thus far. If we have not covered the material, you may still link it to future readings or simply state why you believe it is important.

Several issues immediately surfaced within the above instructions. Firstly, students struggled with the concept of summarizing the materials and often would simply copy the entire article into their assignment. Secondly, in the writing of the third paragraph indicating why the topic was important within the class, the papers indicated the students oft used tautological reasoning as, "This article was important because it is important that we know the information and how it relates to our class." These students struggled with understanding how to take the information learned within the course and apply the theory or knowledge to current events, even after completing 
an example of how to complete the exercise within class time, using current event materials, and showing how to link the article back to the material within the text.

Others struggled with the basic material facts necessary to analyze/summarize the information, as shown within this sentence from a student who was writing on the governmental response to the Puerto Rico crisis after Maria, "this was an important article because Puerto Rico seems to be an island not apart of American." Students, who lack basic factual information from other disciplines or from material that should have been learned during middle/high school, struggle to complete the assignment, as their intellectual knowledge base of real-world factual information is often limited. Additionally, students may struggle with basic spelling/grammar, and not understand how to use the spell check/grammar check tools within Word.

Prose literacy, one of the three literacy domains, is the knowledge and skills needed to perform tasks such as search, comprehend, and use information, and is useful in reading news articles, editorials, brochures, and instructional materials (Baer, Cook, \& Baldi, 2006). Within the 2006 Literacy Report on college students' literacy, there are four levels of proficiency: Below Basic, Basic, Intermediate, Proficient (p. 13).

\subsection{Exercise Using a Paragraph Frame}

The summary paragraph frame used within the study was presented within an article written by Ouellette-Schramm (2015), consisting of an introduction, a main idea statement, and supporting details. As Ouellette-Schramm states (2015), that the paragraph summary not only provides text elements but also provide a syntactic framework using "partial complex sentences, which learners can complete rather than write from scratch" (p. 56). Many issues within summary writing in introductory courses stem from the inability of the student to begin the writing. The syntactic framework allows the students the initial starting point, allowing them to focus on the summary points and not the beginning writings.

Changes were made to the initial directions for the Sociology in the News assignment that included incorporating Ouellette-Schramm's (2015) suggestions, using partial complex sentences. Instead of asking the student to write a paragraph summary of the article, the student was given a paragraph frame for each paragraph. For the first paragraph, the paragraph frame given was "In the article (title of article), (author) explains/discusses/describes/argues that ..." For the second paragraph, the paragraph frame given was "To illustrate this point, the author states...." The third paragraph for the summary writing included instructions along with the paragraph frame:

THIRD PARAGRAPH: Detail why this is an important article for the course. Link the article to the material covered, and/or future readings. Cite your textbook page number. PROMPT: This article relates to what we have learned/are learning in class from a stand point (use the theoretical perspective or the topic).

\section{Methods}

Our goal was to determine whether there was improvement in the writing assessment from Time 1 (Summer) to Time 2 (Fall). In other words did the students write better with or without instructor created paragraph frames?

Is there significant difference in the mean writing assessment scores for Time 1 and Time 2 ?

Is there significant difference in the mean grade level scores for Time 1 and Time 2?

\subsection{Students}

The University of record is public HBCU (Historically Black College or University) located in southwest Georgia in an urban setting with approximately 6,500 students, and is designated as the largest HBCU in Georgia and the 10th largest in the United States. Sixty-nine percent $(69 \%)$ of the undergraduate students identify as Black or African American, with 22.5\% identifying as white, $2.3 \%$ identifying as Hispanic or Latinx, and $0.4 \%$ identifying as Native (American Indian, Alaskan Native, Pacific Islander, including Native Hawaiian). Approximately $66 \%$ of the undergraduate students are female, and the majority (69.5\%) of the students is of traditional age (below 25). Over $95 \%$ of the undergraduate students are from Georgia, in part due to the ability of scholarship funds for instate students and the low cost of attendance. Additionally, the university is an Access to Pathway school, which allows students to enter into an Associate's program and certificate programs. The university also has several career certificate or associate degree program such as dental hygiene, paralegal, paramedic, histologic technician, medical billing/coding, diagnostic medical sonography, medical laboratory and radiologic technology, occupation and physical therapist assistant, and respiratory therapist.

All participants were enrolled in an introduction to sociology course that was a face-to-face class. The times of meeting varied as the summer course met two times a week for 150 minutes during an 8 week semester. The fall course met two times a week for 75 minutes during a full semester (16 weeks). The Sociology in the News assignments were $40 \%$ of the final grade in the course. Participants in the summer course $(N=18)$ were half male and half female. There were students within the course who were in the "move on when ready" accelerated program, or students who were home from other residential institutions. Additionally, there was one older returning non- 
traditional student. Participants in the fall course $(N=41)$, varied greatly with a few students who were in the "move on when ready" accelerated program, and those who were attending college for the first time at a four year residential institution.

\subsection{Materials used in research:}

The study took place over the summer and fall semesters of 2018 using previously submitted "sociology in the news" articles and summary writing exercises submitted by the students via D2L (DesiretoLearn) (Summer $N=89$; Fall $N=220$ ).

\subsection{Design: Between groups}

The research design is a between groups experimental design, as there are two groups of students being assessed: the before prompt group and the after prompt group. The goal is to see if the treatment (prompts) produce better results of the assessment tool constructed for SACSCOC assessment. Additionally, the design can assess if the students who used the prompt were rated higher within the Readability Flesch-Kincaid Grade level produced by Microsoft巴 Office Word.

\subsection{Procedure}

3.4.1 De-identifying and selection of writings for assessment

The study took place over the summer and fall semesters of 2018 using previously submitted "sociology in the news" articles and summary writing exercises submitted by the students via D2L (DesiretoLearn) (Summer $N=89$; Fall $N=220$ ). Identifying information was removed from all of the writing exercises. The next review of the exercises removed any that were copied/pasted directly from the news article or duplicates of previous submission. Writings that remained were processed through Turnitin $(\mathcal{C}$ to prevent the inclusion of plagiarized work that had not been eliminated previously. Twenty four summary writings were randomly selected from each of the two groups remaining writings: writings turned in before the paragraph framing (Summer $2018 n^{l}=24$ ) and writings turned in after using the paragraph framing (Fall $2018 n^{2}=24$ ). Additionally, after randomly selecting the writings, once again the writings were assessed for duplicates or for direct copy. No additional removals were necessary.

3.4.2 Coding Groups

Summer and fall writings were numbered as 1-24 and additionally were given either an A for "After Prompt" and a B for "Before Prompt." Each writing were given a cover sheet that matched the instructions given to the students. Each student's cover sheet contained the writing's word count and a Readability Flesch-Kincaid Grade level. The cover sheet also tracked whether the student followed instructions of posting the title of the article and the hyperlink. Summer writings noted on the cover sheet whether the student wrote a summary of the article in two paragraphs and if the student linked the article to the textbook. The cover sheet of the fall writings note whether the student used the paragraph frames provided for each paragraph, and if the student linked the article to the textbook or what has been learned in the course. The fall cover page also notes whether the student cited page numbers from the text.

\section{Results}

\section{$4.1 \mathrm{Met} / \mathrm{Not}$ Met: Assessment}

The data indicate that there were within the total sample, $47.9 \%(n=23)$ who did not meet the assessment level, and $52.1 \%(n=25)$ who met the assessment. However, a Time/Assessment cross tabulation revealed that the Time 1 had $11(45.8 \%)$ not meet the assessment and $13(54.2 \%)$ meet the assessment. Time 2 had equal numbers of 12 in the met/not met $(50 \%)$.

An independent-samples $t$-test was conducted to compare the assessment scores for Time 1 and Time 2 . There was no significant difference in scores for Time $1(M=0.54, S D=.51)$ and Time $2(M=0.50, S D=.51) ; t(46)=.283$, $p=.78$, two-tailed). The magnitude of the differences in the means (mean difference $=.04,95 \% \mathrm{CI}:-.255$ to .338 ) was moderate (eta squared $=.08$ ).

\subsection{Readability Flesch-Kincaid Grade level scores}

The data reveal that the Readability Flesch-Kincaid Grade level for those in Time 1 range from 5.00 to 17.20 and the range for those in Time 2 is 7.70 to 19.90 .

An independent-samples $t$-test was conducted to compare the grade level scores for Time 1 and Time 2 . There was no significant difference in grade level scores for Time $1(M=10.97, S D=3.64)$ and Time $2(M=10.71, S D=$ $2.72) ; t(46)=.279, p=.09$, two-tailed). The magnitude of the differences in the means (mean difference $=.26$, $95 \%$ CI: -1.61 to 2.12 ) was moderate (eta squared $=.08$ ).

\section{Conclusion}

This empirical study found that using paragraph frames did not significantly improve students' writing skilling 
within the introductory sociology courses analyzed. The authors were not surprised in the analysis as introductory sociology courses are general education requirements and do have varying student levels of achievement in the classroom. Additionally, summer courses tend to have other students who are home for their vacation taking general education courses to transfer to their home institution and also may have students who are taking the course while on summer break from their high school. This could account for the varying Readability Flesch-Kincaid Grade level scores for each time, particularly the summer semester.

\section{Future Research Directions}

As Charatwattananich and Surasin (2019) note, promoting literacy improvement, specifically with English literacy is an important global necessity for competition within the work place and are key to empowering students ( $p$. 107). While their focus were non-native speakers, we also believe that this applies to native English speakers as well, particularly those who are from populations or areas noted for geographic literacy difficulties. Thus, the assessment is now being conducted within an upper level classroom where by the students have been accepted into a program which would require higher level literacy skill sets than at the general education component (Medlin \& Brown, ND). This future research will incorporate those in teacher education courses, using similar assessments from the above article.

An additional assessment of upper level sociology courses is in the process for those who have been in the sociology curriculum for the past year and who have been using prompts in their courses along the way (Brown, Medlin, \& Bennett, ND). This work is a continuation of work featured in Brown, Medlin, and Bennett (2019) and Brown and Medlin (2019).

\section{References}

Anderson, V., \& Hidi, S. (1988). Teaching students to summarize. Educational leadership, 46(4), 26-28.

Baer, J. D., Cook, A. L., \& Baldi, S. (2006). THE LITERACY OF AMERICA'S COLLEGE STUDENTS. American Institutes for Research.

Brown, P., \& Medlin, D. R. (2019). Re-envisioning a Sociology Program Pathway \& Curriculum Map as a Plan of Student Success and Mastery of Outcomes. Poster presented at USG Teaching \& Learning Conference, April 10, 2019, in Athens, Georgia, USA.

Brown, P., Medlin, D. R., \& Bennett, C. R. (2019). Breaking Down the Barriers: Teaching the Complexities of Summarizing via Paragraph Frames. Poster presented at USG Innovations in Teaching Conference, October 25, 2019, in Athens, Georgia, USA.

Brown, P., Medlin, D. R., \& Bennett, C. R. (nd). An Analysis of Summary Writing Across the Curriculum: Writing Prompts across Sociology. Paper in progress.

Cadwallader, M.L., \& C. A. Scarboro. 1982. Teaching Writing within a Sociology Course: A Case Study in Writing across the Curriculum. Teaching Sociology, 9(4), 359-82.

Charatwattananich, M., \& Surasin, J. (2019). Developing an English Literacy Training Program for the Work Context: The Trainer-Researcher Reflection. Journal of Education \& Practice, 10 (24), doi: 10.7176/JEP

Day, J. D. (1986). Teaching summarization skills: Influences of student ability level and strategy difficulty. Cognition and Instruction, 3(3), 193-210.

Finley, T. (2014). Eight Strategies for Teaching Academic Language. Edutopia. Retrieved from https://www.edutopia.org/blog/8-strategies-teaching-academic-language-todd-finley

Goode, J. (2010). Mind the Gap: The Digital Dimension of College Access. The Journal of Higher Education, 81(5):583-618.

Haber, D. (2008). Using today's headlines for teaching Gerontology. Educational Gerontology, 34: 477-488.

Hidi, S., \& Anderson, V. (1986). Producing written summaries: Task demands, cognitive operations, and implications for instruction. Review of educational research, 56(4), 473-493.

Hidi, S., \& Anderson, V. (1992). Situational interest and its impact on reading and expository writing. The role of interest in learning and development, 11, 213-214.

Karasik, R. (2012). Engaged Teaching for Engaged Learning: Sharing Your Passion for Gerontology and Geriatrics. Gerontology \& Geriatrics Education, 33(2), 119-132, DOI: $\underline{10.1080 / 02701960.2012 .661811}$

Lillis, T., \& Turner, J. (2001). Student Writing in Higher Education: Contemporary Confusion, Traditional Concerns. Teaching in Higher Education. 6 (1), 57-68.

Medlin, D. R., \& Brown, P. (nd). Assessing the use of writing prompts in science education courses. Paper in progress.

Migliaccio, T., \& Carrigan, J. (2017). Producing Better Writers in Sociology: A Programmatic Approach. Teaching Sociology, 45(3), 228-239.

Murphree, D. (2014). "Writing wasn't really stressed, accurate historical analysis was stressed": Student Perceptions of In-Class Writing in the Inverted, General Education, University History Survey Course. The History Teacher. 47 (2), 209-219 
Ouellette-Schramm, J. (2015). More than a "Basic Skill": Breaking down the Complexities of Summarizing for ABE/ESL Learners. Journal of Research \& Practice for Adult Literacy, Secondary, and Basic Education, $4(2), 52-57$.

Parrot, H. M., \& Cherry, E. (2014). Process Memos: Facilitating Dialogues about Writing between Students and Instructors. Teaching Sociology, 43 (2), 146-153. https://doi.org/10.1177/0092055X14557440

Relles, S. R., Tierney, W. G. 2013. Understanding the Writing Habits of Tomorrow's Students: Technology and College Readiness. The Journal of Higher Education. 84(4):477-505.

Taraba, J. (2015). Writer's Web: Transitional Words \& Phrases. Retrieved from http://writing2.richmond. edu /writing/wweb/trans1print.html

University of North Carolina Charlotte Website. 2018. Writing Guide: Department of Sociology. Retrieved from https://sociology.uncc.edu/resources-and-forms/writing-guide

Williams, K. (2018). Top 10 Terms Students Need to Know to be Successful on Standardized Tests. Scholastic Teachers. Retrieved from https://www.scholastic.com/teachers/articles/teaching-content/top-10- termsstudents- need-know-be-successful-standardized-tests/

Zwiers, J. (2008). Building academic language: Essential practices for content classrooms. San Francisco, CA: Jossey-Bass Publishers. 